\title{
LUCES Y SOMBRAS EN LA COMPRAVENTA DE VIVIENDA EN CONSTRUCCIÓN EN ESPAÑA. PARTICULARIDADES Y EFECTIVIDAD DE LOS PACTOS PREVIOS
}

\author{
LIGHTS AND SHADOWS IN HOUSING UNDER CONSTRUCTION SALE CONTRACT IN \\ SPAIN. PARTICULARITIES AND EFFECTIVENESS OF PRIOR AGREEMENTS
}

\author{
Silvia Durán Alonso \\ Prof. Dra. de Derecho Civil \\ Universidad Católica San Antonio de Murcia. \\ E-mail: sduran@ucam.edu
}

RESUMEN: La compraventa de vivienda "sobre plano" es un contrato de muy frecuente aplicación práctica en España, que lleva consigo una problemática derivada de sus especiales caracteres, como son el hecho de ser un contrato sobre un bien que aún no existe como tal, y que además está reconocido como bien de primera necesidad. A ello hay que añadir el carácter de profesional del ramo que, normalmente, tiene una de las partes del contrato (el vendedor-promotor), y la falta de regulación unitaria del mismo. Todo ello ha dado lugar a una extensa jurisprudencia sobre los distintos problemas que plantea este negocio jurídico. En el presente artículo, se hace un acercamiento inicial a esta figura, y se analiza la efectividad de los pactos previos que, muy habitualmente, acompañan a este tipo de contratos.

Palabras Clave: Compraventa. Vivienda sobre plano. Vivienda en construcción. Promesa de venta. Pacto de reserva.

\begin{abstract}
The purchase and sale of properties under construction is a very frequent practical application contract in Spain, and carries problems derived from its special characters, like the fact of being a contract on something that does not yet exist, and is recognized as an object of first necessity. Besides that, we must add the professional character of the promoter seller and the lack of unified regulation of the contract. All of it has generated extensive jurisprudence about these issues. In this article is made an initial approach to this figure and the effectiveness of previous agreements, wich usually accompany this type of sales, is analyzed.
\end{abstract}

Keywords: Contract of sale. Housing under construction. Promise of sale

SUMÁRIO: 1.- La compraventa de vivienda "sobre plano". Aproximación al concepto; 2. Consecuencias de considerar la compraventa de vivienda "sobre plano" como contrato mixto o complejo y distinción del contrato de ejecución de obra; 3. Carácter de los posibles pactos previos a la compraventa "sobre plano"; 3.1. El "pacto de reserva" de vivienda; 3.2. La promesa de venta; 3.3. Cuándo estamos ante un contrato de compraventa "sobre plano" perfecto; Conclusiones; Bibliografía 


\section{1. - LA COMPRAVENTA DE VIVIENDA "SOBRE PLANO". APROXIMACIÓN AL CONCEPTO}

Es muy frecuente a día de hoy que el objeto de un contrato de compraventa de vivienda sea una edificación que se encuentre en proyecto o en construcción -contrato conocido comúnmente como "venta sobre plano"-. Este tipo de contratos se caracteriza, entre otras cosas, por el hecho de que la entrega del inmueble se dilata en el tiempo -mientras dura la edificación-, ocurriendo lo mismo con el abono del precio por el comprador. Este importe, además, suele fraccionarse, normalmente, en varios pagos realizados por el adquirente antes de la entrega, abonándose la parte de precio que reste por pagar en el momento en que dicha entrega tiene lugar, concertando el adquirente a estos efectos - en la mayoría de los casos- un préstamo hipotecario. A ello hay que añadir que, en estos contratos de venta de vivienda en construcción, nos encontramos ante un vendedor-promotor, que actúa dentro de su ámbito profesional.

Otra circunstancia que concurre con frecuencia en la venta de vivienda "sobre plano" es el hecho de que la construcción no sólo no está finalizada, sino que habitualmente ni siquiera se ha iniciado su ejecución, por lo que estaríamos ante una "compraventa de cosa futura", es decir, aquella cuyo objeto es inexistente al momento de la venta, figura que tiene su amparo legal en el art. 1.271 CC, conforme al cual "pueden ser objeto de contrato todas las cosas que no están fuera del comercio de los hombres, aún las futuras".

Se han planteado por la doctrina, respecto a los contratos de compraventa de cosa futura, diversas cuestiones, tales como si es un contrato sin objeto, ya que éste no existe, o si dicho objeto sólo está "in itinere"; también se ha defendido que si las cosas no existen "in rerum natura", entonces sólo pueden ser objeto de un precontrato, pero no de un contrato definitivo; otra postura considera que se trata de un contrato con dos fases: la primera, consensual, sobre la cosa y el precio, y la segunda, de ejecución de ese consentimiento precedente; o que la compraventa de cosa futura es, en sí misma, un contrato futuro, pues si no hay transmisión de la propiedad, no se da tampoco cambio de cosa por precio, de manera que el contrato solo debería ser tenido por tal cuando la cosa exista efectivamente ${ }^{1}$.

En España, según ROGEL VIDE ${ }^{2}$, la compraventa que tiene por objeto una cosa futura de la cual se espera que, en efecto, llegue a existir, constituye en todo caso una auténtica compraventa, en la que concurrirían todos sus elementos esenciales y, por tanto, produciría efectos jurídicos obligatorios, con independencia de la inexistencia actual de la cosa. Sin embargo, considera condición necesaria que la cosa llegue, en efecto, a existir, de modo que la efectiva transmisión de la propiedad dependerá de que esa condición, finalmente, llegue a cumplirse. En consecuencia, si la cosa llega a existir con posterioridad, la venta será plenamente eficaz, mientras que, si esto no sucede, será ineficaz, por no concurrir la condición.

Con independencia de la tesis que se considere más acertada, si nos centramos en el tratamiento jurisprudencial del objeto del contrato (la propia vivienda, en proyecto o en construcción), éste ha sido el de considerarla como cosa futura determinada -no como cosa futura incierta-, es decir, como compraventa de cosa futura (emptio rei speratae) y no como compraventa

\footnotetext{
${ }^{1}$ Encontramos diversas teorías, sistematizadas por la doctrina, para dar respuesta a estas cuestiones. Véase PERLINGIERI, P., Il negozi su beni futuri, Vol I: La compraventita di cosa futura, Pubblicazioni della Facoltà Giuridica dell'Università di Napoli, Jovene, Nápoles, 1962, págs. 73 y ss, que incluye en un primer grupo aquellas posturas que niegan que el contrato tenga un objeto, porque consideran que éste no existe o sólo está in itinere y, además, rechazan el carácter condicional del negocio. Por otra parte, en un segundo grupo, incorpora PERLINGIERI las teorías que explican la naturaleza jurídica de la compraventa de cosa futura mediante la figura de la condición. Sin embargo, para RUBINO, D., La compravendita, Giuffré, Milán, 1952, págs. 225 y ss., no se trata de un negocio condicional, al considerar que no se puede someter a condición un requisito esencial del negocio, como es el objeto. ${ }^{2}$ ROGEL VIDE, C., La compraventa de cosa futura, Bolonia, 1975.
} 
de esperanza (emptio spei) ${ }^{3}$. Este dato es importante, ya que implica que el vendedor (promotor) asume la obligación de llevar a cabo las actuaciones necesarias para que la vivienda objeto del contrato llegue a existir, así como de entregarla al comprador, una vez construida. Al mismo tiempo, el vendedor es titular de un derecho de crédito frente al comprador, el cual deberá, a su vez, abonar un precio al vendedor, correlativo a la obligación de éste de entregarle el inmueble ${ }^{4}$.

En este sentido, el Tribunal Supremo se ha pronunciado en múltiples ocasiones sobre la compraventa de vivienda "sobre plano" -por ejemplo, STS de 19 de julio de 2012, Roj: STS 5760/2012-, considerándola como un contrato sobre cosa futura, en el que el vendedor asume la obligación de entrega de la cosa objeto del contrato -una vivienda-, a la que hay que añadir también la obligación de construirla, o promover su construcción. Así pues, el Tribunal Supremo ha venido calificando este negocio jurídico como "compraventa de cosa futura", recogida en el art. $1271 \mathrm{CC}$, en el entendimiento de que la vivienda no existe en el momento en que surge la obligación, pero hay, si no seguridad, sí una alta probabilidad de que llegará a existir (en este sentido, entre otras, SSTS de 30 de octubre de 1989 - Roj: STS 5883/1989- o de 22 de marzo de 1993 - Roj: STS 1805/1993-).

Dicho esto, hay que concluir que, al existir conformidad en el objeto -por estar determinada la vivienda a adquirir, aunque sea solamente mediante su identificación sobre un plano-, y en el precio y demás obligaciones recíprocas de ambas partes, concurren los requisitos esenciales del contrato de compraventa, establecidos en los arts. 1.445 y 1.450 CC. En consecuencia, el contrato es perfectamente válido, sin que sea preciso que la vivienda exista en este momento inicial, para que podamos hablar de nacimiento de la relación contractual, pues es bastante con que dicho inmueble pueda llegar a existir -art. 1.271 del CC-. Tampoco es necesario, en esta primera fase meramente obligatoria o consensual, que el vendedor, obligado a entregar en su momento, tenga poder de disposición sobre la vivienda, dado que no es ahora cuando el mismo se va a ejecutar, sino que en este instante, el compromiso del vendedor (promotor) es el de llevar a cabo una obligación de hacer, tal es la construcción de la edificación.

Por el contrario, la vivienda objeto del contrato sí habrá de existir en el momento en que se haya pactado que debe producirse la entrega, y será exigible entonces al vendedor (promotor) el indicado poder de disposición sobre dicha vivienda, así como la efectiva construcción y consecuente existencia de la misma: si el inmueble no existe, el obligado no podrá entregarlo; si no tiene su libre disposición, el pago no será válido - art. 1.160 del CC-. De este modo, la cosa tiene que existir en el momento estipulado para llevar a cabo la obligación de entrega, y el transmitente debe estar legitimado para disponer de ella también en ese momento, a fin de que el efecto contractual querido se produzca.

En resumen, la compraventa de cosa futura se perfeccionará cuando comprador y vendedor consientan sobre precio y cosa (en nuestro caso, vivienda), aunque ésta no exista todavía o el vendedor no tenga aún poder de disposición sobre ella. Desde el momento en que se presta ese

\footnotetext{
${ }^{3}$ Mientras que la compraventa de cosa futura en su modalidad de emptio rei speratae (compraventa de cosa esperada), es un contrato perfecto desde la prestación del consentimiento, y caracterizado por la obligación del vendedor de no impedir la producción de la cosa e incluso (si así se desprende de lo acordado) de cooperar al nacimiento de ésta -y si la cosa no llega a existir, el vendedor no podrá cumplir su obligación de entrega y nada se deberán recíprocamente las partes-, según RODRIGUEZ MORATA, F. "Comentario al art. 1445 CC", Comentarios al Código Civil, Coord. R.B.R.C., Aranzadi, Pamplona, 2009, pág. 1679, la segunda modalidad de venta de cosa futura (emptio spei o compraventa de esperanza), constituye un contrato aleatorio, de modo que el comprador deberá pagar el precio, aunque la cosa no llegue a existir (asumiendo el comprador el riesgo de la posible inexistencia futura del objeto).

${ }^{4} \mathrm{Al}$ respecto, la STS de 22 de marzo de 1993 (Roj: STS 1805/1993), con cita de otras, literalmente dispone: "los contratos verdaderamente celebrados entre las partes fueron sendas compraventas de cosa futura ("emptio rei speratae"), cuya calificación corresponde (Sentencias de esta Sala de 17 de Febrero de 1967, 3 de Junio de 1970, 30 de Octubre de 1989) a la de una vivienda o local comercial en proyecto de construcción, que el comprador adquiere exclusivamente en función de su terminación, y en la que el vendedor, una vez que la ha terminado, asume la obligación de entregarla al comprador, quien deberá pagar, obviamente, el precio pactado, que es lo ocurrido en el supuesto que nos ocupa".
} 
consentimiento, queda el vendedor obligado a entregar la cosa objeto del contrato, aunque esa obligación no pueda cumplirse hasta un momento futuro. Sin embargo, para que la entrega provoque el efecto real derivado del contrato de compraventa por medio de la tradición, es necesario que la cosa exista y el vendedor esté legitimado para transmitirla en el momento pactado. Por ello, la efectividad del contrato se encuentra a la espera de un acontecimiento futuro. Esto se debe a que el ordenamiento español sigue el sistema romano, en el que la propiedad no se transmite por la mera perfección del contrato, sino que ésta debe ir seguida de la tradición o entrega, que determinará el momento de la consumación de la venta.

Partiendo de todas estas premisas, podemos definir la compraventa de vivienda en construcción o "sobre plano" como aquella modalidad contractual en virtud de la cual, una de las partes, el vendedor-promotor inmobiliario, se obliga a entregar al comprador una vivienda concluida, a cambio de un precio, vivienda que se compromete a construir y que, en el momento de perfeccionarse el contrato, se encuentra aún en proyecto o en proceso de edificación. Así, en esta modalidad de compraventa, en el momento de la firma del contrato las viviendas no tienen existencia actual, sino futura, aunque sí están gráficamente pre-configuradas, en un plano. En este mismo sentido, la STS de 19 de julio de 2012 (Roj: STS 5760/2012) dispone que "el contrato en el que se combina la obligación de construir con la de entrega de un piso o apartamento una vez construido el edificio es un contrato complejo, que requiere que la cosa futura no sea imposible en cuanto a su existencia".

En síntesis, en el contrato de compraventa de vivienda "sobre plano", el vendedor, junto a la obligación de entregar el inmueble objeto del contrato, asume también la de promover su construcción, lo que implica una actividad de gestión y otra ejecutiva: - la actividad de gestión incluye la financiación de la obra, obtención de permisos y licencias, contratación de técnicos (arquitecto, aparejador, proyectista...) e incluso contratación de empresa constructora, si no asume el propio vendedor esa función, si bien esto último es lo más frecuente; - la actividad ejecutiva implica la programación de la obra, propiamente dicha, lo que incluye la dirección facultativa de la misma, construcción, terminación y entrega.

Como conclusión, de la calificación contractual de la compraventa de vivienda en construcción como compraventa de cosa futura, cabe deducir que dicho contrato reúne los mismos caracteres propios de la compraventa ordinaria (contrato consensual, oneroso, y bilateral). Ahora bien, es necesario señalar que, tal y como concluye ATAZ LÓPEZ ${ }^{5}$, se trata de un contrato de naturaleza compleja o mixta, debiendo tenerse presente que una de las partes, el vendedor, asume dos obligaciones principales, causalmente vinculadas: en primer lugar, un facere, que consiste en construir la vivienda objeto del contrato, y en segundo lugar, un dare, materializado en la entrega de dicha vivienda a quien pretende adquirirla.

Así, podemos decir que en el contrato de compraventa de cosa futura -en nuestro caso, el de vivienda en construcción-, por las particularidades del objeto sobre el que recae el contrato, la perfección del acuerdo derivada del consentimiento de ambas partes supondrá para el vendedor la asunción de unas obligaciones de hacer íntimamente conectadas con la finalidad perseguida. El incumplimiento de estas obligaciones estaría directamente relacionado con el incumplimiento de la obligación de entrega, lo que llevaría consigo los correspondientes efectos ${ }^{6}$.

\footnotetext{
${ }^{5}$ ATAZ LOPEZ J., "Compraventa y contrato de obra futura”, Tratado de la compraventa. Homenaje al profesor Rodrigo Bercovitz, Dir. A.C.P., tomo I, Aranzadi, Navarra, 2013, pág. 109.

${ }^{6} \mathrm{Al}$ respecto, v. DIÉZ PICAZO, L. y GULLÓN BALLESTEROS, A., Sistema de Derecho Civil, vol. II, Tecnos, Madrid, 1982, pág. 322.
} 


\section{CONSECUENCIAS DE CONSIDERAR LA COMPRAVENTA DE VIVIENDA "SOBRE PLANO" COMO CONTRATO MIXTO O COMPLEJO Y DISTINCIÓN DEL CONTRATO DE ARRENDAMIENTO DE OBRA}

En el contrato de compraventa de vivienda en construcción, según hemos visto, es necesario que el vendedor lleve a cabo determinadas actividades previas, para que el inmueble llegue a tener existencia efectiva, tales como búsqueda y adquisición de los terrenos en los que se llevará a cabo la edificación, obtención de las licencias administrativas pertinentes, y deberá proceder por sí mismo a la construcción -o en otro caso, encargarse de contratar a la empresa constructora-. Necesitará también hacer frente a la financiación de la obra. Estas obligaciones del vendedor (promotor) pueden dar lugar a que se plantee el problema de dilucidar si estamos realmente ante un contrato de compraventa, o por el contario, ante un contrato de ejecución de obra, con aportación de materiales por el contratista. De hecho, el art. $1588 \mathrm{CC}$, en sede de arrendamiento de obra, señala que el contratista puede ejecutar la obra poniendo únicamente su trabajo, o también suministrando el material. Por ello, si el que suministra los materiales es el contratista, la calificación jurídica del contrato puede plantear algún problema (lo que no sucede cuando es el dueño de la obra quien provee el material).

$\mathrm{Si}$ analizamos las posturas doctrinales al respecto ${ }^{7}$, podemos concluir que depende de la interpretación dada a la voluntad manifestada por los contratantes, que deberá ir dirigida a determinar si se atribuyó más importancia al proceso de construcción del inmueble, en cuyo se trataría de un contrato de ejecución de obra, o si la voluntad de las partes iba dirigida principalmente a la adquisición de la vivienda, encontrándonos entonces ante un contrato de compraventa. En cualquier caso, como bien observa ATAZ LÓPEZ ${ }^{8}$, se considere el negocio como una u otra figura contractual, nos seguiremos encontrando con el problema de que la regulación de la compraventa establecida en el Código Civil español no contiene normas que resuelvan las incidencias derivadas de la previa obligación de construir lo que se va a vender, y viceversa: tampoco la regulación del contrato de arrendamiento de obra regula la posibilidad de enajenar lo construido.

Al respecto, la STS de 28 de noviembre de 1973 (Roj: STS 349/1973), en relación con la compra de una vivienda en construcción, estableció que en el contrato de arrendamiento de obra, el empresario lleva a cabo la actividad que haya encomendado el dueño de la obra, hasta la conclusión de la misma, y durante todo ese tiempo, es dicho dueño, y no el referido empresario, el propietario o titular de los avances, ya que la obligación del agente de la construcción es la de ejecutar (art. $1544 \mathrm{CC}$ ), mientras que en la compraventa de cosa futura, la obligación que asume el vendedor es la de entregar la cosa objeto de venta (art. 1445 CC). Así, en la compraventa de

\footnotetext{
${ }^{7}$ Según PERALES VISCASILlAS, P., "Hacia un nuevo concepto del contrato de compraventa", Revista Criterio Jurídico, $n^{o}$ 3, Pontificia Universidad Javeriana, Santiago de Cali, Colombia, 2013, págs. 17 y 18, doctrinalmente se han propuesto varios criterios para determinar si estamos ante uno u otro contrato, estimándose compraventa si el que ejecuta la obra suministra también el material, puesto que la obligación principal sería un dare y no un facere. Ahora bien, quienes sostienen que estaríamos ante un contrato de obra, consideran que la aportación de materiales por quien lleva a cabo la construcción no desnaturaliza tal contrato de obra, ya que esta aportación de materiales es meramente accesoria, subsumiéndose el dare en el facere, según MANRESA Y NAVARRO, J.M., Comentarios al Código Civil español, Reus, Madrid, 1969, pág. 702. Distinto de los anteriores es el criterio de la producción ordinaria, que se basa en la fabricación o producción del objeto: estaríamos ante una compraventa si la fabricación es en serie y obra en caso contrario. Por último, también hay autores que estiman que se trataría de un contrato mixto: de compraventa en relación con los materiales, y de obra en relación con la prestación de trabajo. En este sentido, por todos NAVARRO PEREZ, J.L., La compraventa civil. Antecedentes, comentario doctrinal, jurisprudencia y formularios, Comares, Granada, 1993, pág. 84; también BORRELL SOLER, A., El contrato de compraventa según el Código Civil español, Bosch, Barcelona, 1952, pág. 64.

${ }^{8}$ ATAZ LOPEZ, "Compraventa y contrato de obra futura", op. cit., pág 109.
}

Revista de Direito Brasileira | Florianópolis, SC | v. 27 | n. 10 | p.300-314 | Set./Dez. 2020 
vivienda futura, las partes acuerdan la entrega de la cosa, obligación que asume el vendedor, mientras que en el arrendamiento de obra, la obligación del agente es ejecutar lo que se le encarga?

Es también interesante destacar que, mientras en el contrato de obra es frecuente que el adquirente de la construcción sea además titular del suelo dónde la misma se lleva a cabo, y va adquiriendo de forma progresiva lo que en él se edifica, en la compraventa de vivienda en construcción, el adquirente ni es propietario del suelo, ni adquiere lo edificado gradualmente. Este argumento, aparte de los ya indicados, puede resultar de utilidad para calificar el contrato como compraventa o como arrendamiento de obra. Si bien, en cualquier caso, debe estarse a la voluntad de los contratantes para atribuir al negocio una u otra calificación, valorando el que las partes hayan otorgado mayor importancia bien al inmueble que va a ser entregado, o bien al proceso de construcción o edificación -es decir, al dare o al facere-, de modo que a quién corresponda calificar el contrato, deberá determinar cuál fue la voluntad real de las partes ${ }^{10}$.

Dicho criterio de interpretación será el que deba tenerse en cuenta en aquellos contratos de vivienda en construcción en que intervenga una promotora, vendiendo una parcela (normalmente incorporada en una urbanización), obligándose además a ejecutar las obras necesarias para la edificación de una vivienda en dicha parcela, mientras que el comprador se obliga a anticipar fondos. En estos casos, la finalidad última del negocio es transmitir una vivienda futura, por eso, más que ante dos contratos diferentes - de compraventa y de ejecución de obra con aportación de materiales-, estaríamos ante una compraventa de vivienda a construir, más aún si no se ha otorgado escritura pública de la parcela antes de empezar las obras, y se ha fijado el abono de un precio unitario y total por la parcela y la vivienda a construir mediante entregas parciales, sin distinción alguna entre uno u otro concepto, retrasando el momento de otorgamiento de escritura final de compraventa a la fecha en que la edificación de la vivienda esté concluida ${ }^{11}$.

Ahora bien, en todo caso, las prestaciones de hacer son debidas por el vendedor-promotor $\mathrm{y}$, en consecuencia, exigibles, de lo que debemos concluir que la compraventa de vivienda "sobre plano" o en construcción es una figura compleja en su contenido, ya que la obligación del promotor vendedor de entregar la vivienda se encuentra indisolublemente unida a la de ejecutar la obra, y además dicha ejecución debe ajustarse a las particularidades que se desprendan del plano incorporado al contrato (o a las características concretas contenidas en el propio contrato). Por ello, responderá el promotor ante el comprador no solo por su condición de parte vendedora en el contrato de compraventa, sino también por su carácter de agente de la edificación ${ }^{12}$. En este sentido, ATAZ LOPEZ considera que se trata de "situaciones intermedias, en las que están presentes las obligaciones propias de ambos tipos contractuales", por lo que, antes que discutir la calificación del contrato, es preferible identificar las zonas de conflicto y determinar cuándo deberá prevalecer la regulación del contrato de obra y cuando la del de compraventa ${ }^{13}$.

Consecuencia de todo lo anterior, es que también parece directamente relacionada con la condición del contrato de compraventa "sobre plano" como contrato mixto o complejo, la obligación que, normalmente, se estipula a cargo del comprador de llevar a cabo entregas

\footnotetext{
${ }^{9}$ El Tribunal Supremo ha tenido ocasión de pronunciarse sobre las similitudes entre ambos negocios jurídicos. Por todas, STS de 11 de febrero de 2010 (Roj: STS 447/2010).

${ }^{10}$ FERRÁNDIZ GABRIEL, J.R., "Compraventa de cosa futura", El Contrato de Compraventa. Cuadernos de Derecho Judicial XXI, Consejo General del Poder Judicial, Madrid, 1993, págs. 88 y ss. Al respecto, encontramos también la STS de 18 de enero de 2013 (Roj: STS 679/2013).

11 ALONSO SAURA, M.P., "El tiempo en la entrega de la vivienda objeto de compraventa en proyecto o en construcción en situaciones de crisis económica", Discurso leído el día 30 de junio de 2011 en el acto de recepción como Académico de Número de la Real Academia de Legislación y Jurisprudencia de la Región de Murcia, pág. 23.

${ }^{12}$ Así, el art. 17 LOE, al regular la responsabilidad civil de los agentes intervinientes en el proceso de edificación, dispone en su apartado 9 que "las responsabilidades a que se refiere este artículo se entienden sin perjuicio de las que alcanzan al vendedor de los edificios o partes edificadas frente al comprador conforme al contrato de compraventa suscrito entre ellos, a los artículos 1.484 y siguientes del Código Civil y demás legislación aplicable a la compraventa".

${ }^{13}$ ATAZ LOPEZ, "Compraventa y contrato de obra futura", op. cit, pág. 109.
}

Revista de Direito Brasileira | Florianópolis, SC | v. 27 | n. 10 | p.300-314 | Set./Dez. 2020 
anticipadas a cuenta del precio total del inmueble, que, por otra parte, y como contraprestación, deberán destinarse por el vendedor-promotor a financiar la construcción de la vivienda. Esto se debe a que, en realidad, con el pago de tales cantidades anticipadas no estaría el adquirente sólo abonando el precio, sino que, además, estaría también haciendo frente a la propia financiación de la construcción de la vivienda adquirida, obligación que se correspondería con la propia del promotor de edificar el inmueble conforme a lo estipulado en el contrato. Todo ello sin perjuicio, naturalmente, de que dichas cantidades anticipadas se imputen finalmente al precio total de la vivienda -toda vez que ese precio ha sido calculado por la propia parte vendedora-promotora teniendo en cuenta los gastos de edificación-.

En defensa de esta postura, que considera este contrato como una figura mixta, debe recordarse también el hecho de que, si después de la adquisición del inmueble, el comprador se encontrara con la existencia de vicios o defectos constructivos en la vivienda, serían de aplicación los preceptos de la Ley de Ordenación de la Edificación, relativos a la responsabilidad del promotor y demás agentes de la edificación, y no los arts. 1484 y ss. CC, reguladores del saneamiento por vicios ocultos en la compraventa.

\section{CARÁCTER DE LOS POSIBLES PACTOS PREVIOS A LA COMPRAVENTA "SOBRE PLANO"}

En la contratación inmobiliaria, especialmente cuando el objeto de la venta es una vivienda en construcción o "sobre plano", es frecuente la utilización de determinadas fórmulas, como son la "promesa de compraventa", "reserva de compraventa" o "contrato de reserva". Cualquiera de ellas es perfectamente lícita, en virtud del principio de autonomía de la voluntad que preside nuestro ordenamiento jurídico. Si bien, aunque, en efecto, pueden ser simples tratos preliminares, o precontratos, si concurren determinadas circunstancias, podemos estar ante un auténtico contrato de compraventa de vivienda en construcción.

Así, en la práctica es frecuente que, antes de la firma de la escritura pública de compraventa definitiva, el comprador haya suscrito con anterioridad un contrato de promesa de venta, o bien de reserva, de opción de compra, o incluso una compraventa con precio aplazado. Este tipo de acuerdos, aunque pueda parecerlo, en principio no confieren la condición de propietario al adquirente, ya que en nuestro ordenamiento jurídico -como ya se ha expuesto-rige la teoría del título y el modo, que exige la entrega real de la posesión (generalmente, tratándose de inmuebles, mediante otorgamiento de escritura pública, forma de entrega prevista en el art. 1462 CC) para que haya transmisión de la propiedad.

Cualquiera que sea la forma contractual que, en su caso, se emplee en esta fase previa a la compraventa, habrá que estar a las reglas generales sobre interpretación de los contratos (arts. 1281 y ss. CC), de difícil aplicación en muchas ocasiones. Esta tarea interpretativa, normalmente, corresponderá al juzgador de primera instancia, que llevará a cabo una labor de calificación del contrato, a fin de determinar la verdadera naturaleza del mismo. A dicho efecto, tomaremos como base la doctrina consolidada del Tribunal Supremo, conforme a la cual "los contratos son lo que son y la calificación no depende de las denominaciones que le hayan dado los contratantes", ya que, para calificar un contrato, hay que estar a su contenido real, a lo efectivamente convenido por las partes, "con prevalencia de la intención de las mismas sobre el sentido gramatical de las palabras" (SSTS 15 de diciembre de 2005, Roj: STS 7127/2005, y 2 de marzo de 2007, Roj: STS 1174/2007, entre otras).

En consecuencia, de la calificación atribuida al contrato, independientemente de la denominación dada por las partes, dependerá el régimen jurídico que le será aplicable, por lo que habrá de determinarse cuándo realmente se ha concertado un contrato de compraventa sobre plano, y cuando nos encontramos ante una figura jurídica diferente. El problema surge cuando el promotor emplea estos negocios jurídicos previos en beneficio propio, con menoscabo de los intereses del 
adquirente de la vivienda, que normalmente desconocerá los matices jurídicos que implican (conviene recordar, además, que estos precontratos son unilateralmente redactados por el vendedor-promotor y presentados para su firma al comprador, al que se deja escaso, o incluso nulo, margen de maniobra).

\subsection{El "pacto de reserva" de vivienda}

El denominado pacto o contrato de reserva surge como consecuencia del principio de autonomía de la voluntad, sin reflejo normativo alguno en derecho español. En la época del "boom" inmobiliario, se empleaba frecuentemente a pie de obra, cuando a veces ni siquiera se habían obtenido las licencias oportunas, a fin de captar posibles compradores en su primera visita. Por ello, en la práctica es frecuente encontrar que, en muchas ocasiones, se caracterizan por una absoluta indeterminación.

Este tipo de contrato de reserva realmente no es más que un acuerdo de voluntades, en virtud del cual una persona interesada en adquirir una vivienda entrega a otra, a su vez interesada en venderla, una cantidad para "garantizar de la exclusión de terceros adquirentes". Así, estamos ante un derecho de adquisición preferente, originado en virtud de un acuerdo, que plantea ciertas dudas en cuanto a su posible distinción del "derecho de opción", en la medida que, en virtud de este acuerdo, ciertamente, se estaría atribuyendo al que reservó la facultad de poder adquirir el bien. Si bien, la finalidad de la opción no se limita a reservar durante un plazo de tiempo el bien inmueble, sino que va más allá, al permitir al posible comprador la adquisición de forma unilateral, si el derecho de opción se hubiera inscrito en el Registro de la Propiedad ${ }^{14}$.

En la práctica general, el "pacto de reserva" retrasa a un momento ulterior la determinación de los elementos esenciales del contrato que las partes pretenden celebrar, en el cual ya consentirán sobre la cosa y el precio. Pese a la aparente claridad del término "reserva", lo cierto es que, en la práctica, las diferentes fórmulas jurídicas empleadas por las partes en sus acuerdos, encubren con frecuencia distintas figuras contractuales, lo que obliga a los Tribunales a realizar una constante labor interpretativa.

\footnotetext{
${ }^{14}$ Define la STS de 2 de junio de 2009 (Roj: STS 3301/2009) el derecho de opción como "un convenio en virtud del cual una parte concede a otra la facultad exclusiva de decidir la celebración o no de otro contrato principal de compraventa, que habrá de realizarse en un plazo cierto, y en unas determinadas condiciones, pudiendo también ir acompañado del pago de una prima por parte del optante, constituyendo sus elementos principales: la concesión a éste (al optante) del derecho a decidir unilateralmente respecto a la realización de la compraventa, la determinación del objeto, el señalamiento del precio estipulado para la futura adquisición y la concreción de un plazo para el ejercicio de la opción, siendo por el contrario elemento accesorio el pago de la prima”.

La finalidad del derecho de opción consiste en asegurar que una de las partes de ese contrato definitivo no pueda negociar o perfeccionar el contrato con otra persona distinta a la otra parte, titular del derecho de opción. Así, estamos ante un contrato preparatorio de otro, aunque no es un precontrato en sentido técnico, al tener una causa propia (la irrevocabilidad de una oferta o voluntad contractual). Son múltiples los contratos que pueden prepararse mediante una opción, pero el más frecuente en la práctica es la "opción de compra”, en la que el concedente es el eventual vendedor, ya que deberá asumir tal posición, si el optante ejercita su facultad de opción, TORRES LANA, J.A., "Perfección de la compraventa mediante el ejercicio de una opción", Tratado de la compraventa. Homenaje al profesor Rodrigo Bercovitz, Dir. A.C.P., tomo I, Aranzadi, Pamplona, 2013, págs. 435 a 437.

La única referencia normativa del derecho de opción en España se encuentra en el art. 14 del Reglamento Hipotecario. Los elementos que lo integran son el plazo para su ejercicio, y el precio estipulado para la adquisición del inmueble y, en su caso, para conceder la opción. Uno de los aspectos importantes de esta figura ha sido señalado por la RDGRN de 20 de mayo de 2005: "la jurisprudencia, la doctrina científica y la de este Centro Directivo han admitido la inscribilidad y eficacia del pacto de ejercicio unilateral de la opción sin necesidad de la intervención del concedente del derecho; ahora bien: tal innecesariedad de su consentimiento ha de tener su base en el exacto cumplimiento de los requisitos inscritos para la inscripción a favor del optante”. TORRES LÓPEZ, A., "La protección del comprador de la vivienda en los momentos previos a la consumación del contrato", Cuadernos de Derecho Judicial 1/2009, Consejo General del Poder Judicial, Madrid, 2009, págs. 35 y 36.
}

Revista de Direito Brasileira | Florianópolis, SC | v. 27 | n. 10 | p.300-314 | Set./Dez. 2020 
Al respecto, puede decirse que, en general, el pacto de reserva se equipara a un contrato preliminar, precontrato, o pactum de contrahendo. Esto se corresponde con la naturaleza propia de la reserva: si reservar supone destinar algo exclusivamente a una determinada persona, entenderemos que la reserva implica que la promotora acuerda con los interesados la enajenación de un inmueble concreto, para que éstos, con exclusión de otras personas, también interesadas, puedan adquirirlo, comprometiéndose, de este modo, a vendérselo (SAP Barcelona 3 de junio de 2008, Roj: SAP B 5824/2008) ${ }^{15}$.

El pacto de reserva se limitaría, en consecuencia, a aquellos supuestos de simple acuerdo de voluntad de entrega de una cantidad en "garantía de la exclusión de terceros adquirentes", es decir, un compromiso del promotor de reservar una concreta vivienda, o un trato preliminar, que realmente no expresa el consentimiento del vendedor para entregar definitivamente la vivienda, ni el del adquirente para pagar el precio. En este sentido, la SAP Almería de 31 de mayo de 2006 (Roj: SAP AL 450/2006) calificó un pacto de estas características como un "derecho de reserva de vivienda a construir", rechazando su calificación como contrato de compraventa e incluso como precontrato, por no entender suficientemente especificado el efectivo consentimiento de las partes de celebrar la compraventa en ese momento, ni tampoco de suscribir dicho contrato más adelante. En idéntico sentido, la SAP de Castellón de 30 de noviembre de 2007 (Roj: SAP CS 1170/2007) resolvió en un supuesto similar que se estaba ante una simple reserva, y no una compraventa, no solo en virtud del propio contenido del contrato suscrito, sino también por lo reducido del importe abonado en concepto de reserva, en relación con el precio total del inmueble ${ }^{16}$. Atendiendo a lo anterior, un criterio esencial que debería concurrir para determinar que, en efecto, estamos ante un simple pacto de reserva y no ante una compraventa perfecta, sería el de la proporcionalidad (o falta de ella) entre la cantidad objeto de la reserva y precio final de la vivienda.

Un problema que plantean estos simples pactos o contratos de reserva es el relativo al concepto en el que debe considerarse recibida la cantidad -o "señal"- entregada por el futuro adquirente, ya que si admitimos -como hemos hecho- que contrato de reserva es un negocio distinto del contrato de compraventa posterior sobre la vivienda (al ser un acuerdo susceptible de futuras modificaciones, ya sea en el objeto -cabida o localización exacta del inmueble, por ejemplo-, o incluso en las partes), y si entendemos que el objeto de este contrato de reserva es la adquisición de un derecho preferente sobre una vivienda futura, con garantía de exclusión de terceros sobre dicha adquisición, debemos concluir que el importe que se abone en concepto de señal sería la contraprestación de ese derecho o garantía de exclusión. Todo ello sin perjuicio de que las partes, en libertad para establecer los pactos que consideren oportunos, hayan acordado que, para el caso de que llegara a suscribirse, en su momento, el contrato de compraventa, la cantidad entregada en concepto de reserva se aplique al precio final de la vivienda, o estipulen que, en caso de incumplimiento por parte del vendedor del deber de reserva o garantía, éste. en concepto de indemnización, restituya al adquirente la cantidad percibida por duplicado (o también, al contrario, la pierda el eventual comprador, si finalmente no suscribiera el contrato).

15 MERIDA ABRIL, C., "El contrato de compraventa de inmuebles y su resolución", Derecho inmobiliario: Problemática actual, Manuales de Formación Continuada 50/2009, tomo II, Consejo General del Poder Judicial, Madrid, 2009, págs. 9 y ss.

${ }^{16}$ Así, se indica en dicha resolución que "no nos encontramos ante un contrato de compraventa, ni siquiera como se establece en la sentencia de instancia, ante una promesa de venta, puesto que en el contrato se señala, tanto en el encabezamiento, como en la estipulación tercera, "están interesados en adquirir la reserva de compra" "la reserva de compra" y "señal para reserva", lo que supone que la suscripción del tan citado documento, conlleva la aceptación de todo su contenido por quien lo firma (TS 29.9.1996), por tanto resulta meridiano que lo descrito, es una relación contractual relativa a una reserva sobre la base de una futura construcción, a cuyo fin se entrega una señal para reserva de diez mil euros, cantidad que resulta insignificante en relación con el precio total acordado de doscientos treinta y cuatro mil euros sin IVA, sobre los inmuebles a construir, y consecuentemente, una vez construidas las fincas relativas al contrato, se haría efectiva la compraventa, siendo obvio que lo firmado en el presente caso, no es un contrato de compraventa, sino una simple reserva de unas viviendas que se construirán, lo que supone un derecho preferente de quien acepta la reserva".

Revista de Direito Brasileira | Florianópolis, SC | v. 27 | n. 10 | p.300-314 | Set./Dez. 2020 
Por todo ello, si el pacto de reserva es un negocio jurídico distinto de la compraventa, la cantidad que se hubiera abonado en concepto de tal reserva no debe tampoco considerarse entregada en concepto de arras -ni confirmatorias ni penitenciales-, con independencia de la denominación dada por las partes a dicha cantidad, al no existir, en realidad, acuerdo sobre el precio y la cosa, lo que implica que, en realidad, tampoco existe contrato de compraventa como tal, según se desprende de los arts. 1445 y $1454 \mathrm{CC}^{17}$.

Finalmente, en lo que se refiere a las consecuencias de un eventual incumplimiento del pacto de reserva, respecto a si éste podría llevar consigo la indemnización por los daños y perjuicios, al respecto, en la SAP Lérida de 23 de febrero de 2005 (Roj: SAP L 160/2005) el Tribunal consideró que, al ser meros tratos preliminares, no procedía el abono de la indemnización de daños y perjuicios interesada. Si bien, entiendo que esa postura debería considerarse, ya que, aunque estemos ante una simple reserva de inmueble, si se hubiera acreditado la existencia de daños y perjuicios derivados del incumplimiento del pacto preliminar, en principio no parece que haya ningún obstáculo legal para obtener el correspondiente resarcimiento.

\subsection{La promesa de venta}

A diferencia del pacto de reserva, la promesa de venta sí aparece regulada en el art. 1.451 $\mathrm{CC}$, conforme al cual "la promesa de vender o comprar, habiendo conformidad en la cosa y en el precio, dará derecho a los contratantes para reclamar recíprocamente el cumplimiento del contrato. Siempre que no pueda cumplirse la promesa de compra y venta, regirá para vendedor y comprador, según los casos, lo dispuesto acerca de las obligaciones y contratos en el presente libro".

La esencia de la promesa bilateral de compra y venta, a la que se refiere el art. $1451 \mathrm{CC}$, radica en diferir para un momento posterior la perfección y entrada en vigor del contrato proyectado, quedando mientras tanto las partes solamente ligadas por el peculiar vínculo que aquélla produce. Esta suerte de precontrato contiene las bases del contrato propiamente dicho y consiste, estrictamente, en "quedar obligado a obligarse", resultando plenamente diferenciable la promesa bilateral de compra y venta del contrato definitivo de compraventa, extremo que depende de la voluntad de los interesados y de los pactos a través de los cuales hayan fijado sus obligaciones respectivas (SSTS 20 de abril de 2001, Roj: STS 3259/2001 y 3 de junio de 2002, Roj: STS 3986/2002).

Siguiendo a ATAZ LOPEZ ${ }^{18}$, podemos diferenciar esta figura del contrato de compraventa propiamente dicho, partiendo del hecho de que la promesa puede considerarse como un precontrato, es decir: un acuerdo en virtud del cual las partes se comprometen a celebrar posteriormente un contrato distinto, que aún no se habría celebrado, e incluso podría no llegar a celebrarse. La delgada línea existente entre la promesa de venta y la compraventa propiamente dicha da lugar a que, con frecuencia, las promotoras empleen este tipo de acuerdos para captar de forma rápida la voluntad del adquirente, sin incluir, muchas veces, elementos del negocio que podrán llevar al adquirente a dudar acerca de cerrar la operación de forma definitiva.

Ahora bien, es necesario tener en cuenta que, aunque la promesa de venta tenga, en principio, un carácter meramente preparatorio de la compraventa posterior, sí debería incorporar, al menos, los elementos considerados esenciales de la futura adquisición. Pese a ello, es frecuente encontrar en la práctica ejemplos de sucintas promesas de venta cuyo objeto principal, más que

\footnotetext{
17 Al respecto, la STS de 29 de julio de 1997 (Roj: STS 5327/1997) dispuso claramente que "sean las arras confirmatorias o penitenciales, han de tener como referencia un determinado contrato de compraventa en el que está especificado el objeto y precio; de otra manera, no podría desplegar sus efectos: ¿qué rescindiría o confirmaría entonces?". En idéntico sentido, SAP Segovia de 28 de abril de 2005 (Roj: SAP SG 109/2005).

18 ATAZ LOPEZ, J., “Artículo 1451”, Comentarios al Código Civil, Dir. R.B.R.C., Tirant lo Blanch, Valencia, 2013, pág. 10.229
} 
fijar los elementos de la futura compraventa, se centra en determinar las penalizaciones a cargo del eventual comprador para el caso de incumplimiento de su compromiso de adquirir el inmueble. Por todo ello, este tipo de acuerdos son más arriesgados para el adquirente que el hecho de suscribir una compraventa definitiva con precio aplazado, ya que ésta última sí debe incluir todos los elementos, cláusulas y condiciones de la misma.

Al margen de lo anterior, otra cuestión problemática viene del hecho de que aquél que se compromete a reservar una vivienda, se está obligando, por ende, a venderla en un futuro. Esta circunstancia ha dado lugar a que, con frecuencia, las resoluciones judiciales califiquen los pactos de reserva como promesa unilateral de venta, o los acuerdos de promesa de venta como compraventa propiamente dicha ${ }^{19}$. En este sentido, la SAP Granada de 14 de julio de 2006 (Roj: SAP GR 1180/2006), al examinar un documento privado denominado por las partes "Documento de reserva" de una vivienda, que indicaba en una de sus cláusulas: "La firma del contrato privado de compraventa tendrá lugar...", el tribunal determinó que se trataba de una promesa de venta y no de una compraventa, según se desprendía del propio texto del documento, al entender que si las partes hubieran pretendido otorgar una compraventa (en lugar de una promesa), "no hubieran tenido sentado referirse a la finca del contrato privado de compraventa, ni el documento hubiese sido de reserva sino de venta. Precisamente con la promesa las partes contraían la obligación de efectuar posteriormente una compraventa"20.

\subsection{Cuándo estaríamos ante un contrato de compraventa "sobre plano" perfecto}

De todo lo anteriormente expuesto deducimos que es la exacta determinación o concreción de la cosa objeto del contrato (vivienda) y del precio de la misma, asumiendo quiénes suscriben ese acuerdo las obligaciones propias de comprador y vendedor, concurriendo los requisitos legales (art. $1450 \mathrm{CC}$ ), lo que determina que los pactos o acuerdos de reserva, o promesas de venta, examinados sean calificados jurídicamente por los Tribunales como contratos de

\footnotetext{
${ }^{19} \mathrm{Al}$ respecto, la STS de 3 de Junio de 2002 (Roj: STS 3986/2002), para distinguir un precontrato de compraventa de un contrato definitivo, indicó que "la esencia de la promesa bilateral de compra y venta (a la que se refiere el artículo 1451 del Código Civil) radica en diferir para un momento posterior la perfección y entrada en vigor del contrato proyectado, quedando mientras tanto solamente ligadas las partes por el peculiar vínculo que produce el precontrato, que contiene el proyecto o ley de bases del siguiente y que consiste estrictamente en quedar obligado a obligarse" (STS de 28 de noviembre de 1994); y que "la distinción entre contrato definitivo y mera promesa ha de buscarse en la voluntad de las partes contratantes y en los pactos a través de los cuales hayan constituido sus recíprocas obligaciones; en este caso, la intención de los partícipes en el negocio es clara: se concreta la cosa, se fija el precio y la forma de pago, se determina que el comprador se subroga en la hipoteca que grava la finca desde la fecha de su firma, 30 de diciembre de 1995, no de las cargas que hubiere a partir del 15 de enero siguiente. (...)

Pues bien, en el documento privado objeto del litigio concurren todos los presupuestos necesarios para considerar el contrato como una compraventa, que quedó perfeccionada y es vinculante por consecuencia del convenio plasmado". ${ }^{20}$ También lo califica de "promesa de venta" la SAP Las Palmas de 10 de junio de 2008 (Roj: SAP GC 2089/2008), sentencia que revocó la del juez de instancia -que había desestimado la demanda (la cual interesaba que se condenara a la parte demandada al cumplimiento del contrato privado, así como al otorgamiento de escritura pública de compraventa), fundamentando que el documento privado no era tal promesa de venta, sino simplemente un pacto de reserva, formalizado en una especie de recibo, que entendió el juzgador que se trata de un simple trato preliminar, el cual no podía implicar que el demandado estuviera prestando su consentimiento para entregar la vivienda, ni el demandante para abonar el precio. Para llegar a esa concusión, se basaba en que el documento objeto de análisis habla de reserva de vivienda, pero no de entrega-. Ahora bien, por el contrario, la Audiencia consideró que "el contrato suscrito el 17 de octubre de 2005 es una promesa de venta dado que existe una clara conformidad en el precio en él determinado, y en la cosa, la vivienda núm. 13 del tipo $V$, de la promoción Residencial Malvasía, además de la entrega de 6.000 euros, con la naturaleza de arras confirmatorias, como señal de la celebración del contrato, que será deducida del precio de la compraventa. Por tanto, de conformidad con lo dispuesto en el art. 1451 C Civil, y de la doctrina jurisprudencial mencionada, no resultando patente la voluntad de excluir los efectos de la compraventa, procede estimar el recurso, revocando la sentencia y estimar la demanda, condenando a la demandada al cumplimiento del contrato de 17/10/2005, así como al otorgamiento de la escritura pública de compraventa a favor del actor".
} 
compraventa perfectos. La labor interpretativa de dichos Tribunales, en estos casos, está dirigida a la delimitación o diferenciación entre las figuras de reserva o promesa de venta y compraventa propiamente dicha.

Así, en este sentido, siguiendo los presupuestos legales y jurisprudenciales analizados, la SAP Zaragoza de 20 de diciembre de 2002 (Roj: SAP Z 2949/2002), tras examinar un "compromiso de reserva" en el que estaban perfectamente determinados el inmueble objeto de la venta y el precio, y se acordaba la entrega de una concreta cantidad a cuenta del precio y unos plazos precisos para el pago, entendió que estábamos ante un contrato de compraventa perfecto. De igual forma, la SAP Tarragona de 3 de septiembre de 2007 (Roj: SAP T 1443/2007) apreció, al analizar el documento que era objeto de autos, denominado "de reserva", que, al incluir tanto el inmueble objeto de la venta como el precio definitivo del mismo y la forma de pago, podría considerarse como una opción de compra ${ }^{21}$; otra posibilidad que barajó la resolución es que se tratara de una compraventa propiamente dicha, por incorporar "todos los requisitos precisos para el perfeccionamiento de la compraventa (...), es decir se da la concurrencia de los dos consentimientos”, decidiendo, finalmente que era un auténtico contrato de compraventa, por incorporar los presupuestos esenciales de dicho contrato, conforme al art. $1445 \mathrm{CC}^{22}$.

Como conclusión, podemos decir que, generalmente, la jurisprudencia distingue dos posibilidades: bien que no estén perfectamente definidos todos los elementos del contrato, o bien que dichos elementos sí aparezcan claramente determinados. En el primer caso, se suele calificar como un pacto de reserva o promesa de venta. Es indiferente el nombre que utilicen las partes para designar el acuerdo descrito, puesto que, en la práctica, el resultado será el mismo: una garantía de exclusión de terceros sobre la compraventa futura de un inmueble, determinado en mayor o menor medida, por parte del futuro vendedor (promotor), a cambio de un compromiso de compra de dicho inmueble por parte del eventual comprador, interviniendo en la mayoría de los casos la entrega de una cantidad -señal- por parte del comprador, como contraprestación de esa reserva o garantía.

\section{CONCLUSIONES}

Después del análisis de las posturas doctrinales y jurisprudenciales al respecto, debemos concluir que, cuando nos referimos al contrato de compraventa de vivienda "sobre plano" o en construcción, no podemos considerarlo solo como un simple contrato de compraventa de cosa futura específica, sino que estamos ante un contrato de carácter mixto o complejo, que supone para el vendedor (promotor), además de la asunción de la obligación de entrega -principal y típica de la compraventa-, adoptar obligaciones propias del arrendamiento de obra (concretamente, la de construcción del inmueble conforme a las características estipuladas). Dicho carácter mixto o complejo que se atribuye a la compraventa de vivienda "sobre plano" es consecuencia necesaria

\footnotetext{
21 "Pues, si no se quiere que el pacto quede a la entera y libre disposición del vendedor, lo que chocaría con la prohibición del artículo 1256 del CC, habría de dársele el efecto de que el vendedor se comprometía a conservar a disposición del vendedor el inmueble por cierto tiempo, es decir le otorgaba la facultad de optar”.

22 Así, dispuso el Tribunal que "La anterior alternativa nos la resuelve la sentencia del TS de 22 de octubre de 1992, que en un supuesto prácticamente idéntico al de autos, señala respecto del documento que extracta: que es evidente, pues, que dicho documento encierra un auténtico contrato de compraventa, pues en el mismo constan los presupuestos esenciales del art. 1445 CC, en cuanto a la esencialidad de la entrega de cosa determinada y la obligación de pagar por ello un precio cierto, en relación, asimismo, con lo dispuesto en el art. 1450, que prescribe que la perfección de la compraventa será obligatoria para ambos si hubiesen convenido en la cosa objeto del contrato, y en el precio, aunque ni la una ni el otro se hayan entregado". En idéntico sentido, la SAP Málaga de 27 de septiembre de 2007 (Roj: SAP MA 1891/2007) razona que "el contrato suscrito no contenía una mera reserva para la adquisición de una vivienda no concretada ni en su identificación ni en su precio, sino todo lo contrario, pues se reflejan en el documento firmado no sólo la voluntad de las partes de comprar y vender recíprocamente (promesa bilateral de venta) una vivienda descrita de forma detallada en cuanto a su ubicación y extensión, sino que además se concreta el precio y las condiciones y plazos de entrega. En definitiva, se contiene en el contrato los elementos esenciales que delimitan la existencia del contrato en general (sujetos, objeto y causa) y de la compraventa en particular".
}

Revista de Direito Brasileira | Florianópolis, SC | v. 27 | n. 10 | p.300-314 | Set./Dez. 2020 
tanto de la especialidad de su objeto, como de lo insuficiente que resulta la regulación del contrato de compraventa en nuestro Código Civil para hacer frente a los problemas dimanantes de la previa obligación de construir.

Además, también consecuencia de este carácter mixto referido es la obligación propia del comprador de entregar determinadas cantidades de dinero de forma anticipada, respecto de las cuales, en principio, el promotor-vendedor no tendría libre disponibilidad, ya que debería destinarlas a una concreta finalidad, tal es la financiación de la construcción del inmueble. Estas cantidades anticipadas estarían, por tanto, cumpliendo una doble función: la de pagar el precio del inmueble -propia de la compraventa- y la de financiación de la edificación -típica del arrendamiento de obra que, a su vez, encuentra su contraprestación en la obligación por el promotor de construir según lo pactado-.

En lo que se refiere a la distinción de los posibles pactos previos de reserva o promesa de venta de un verdadero contrato de compraventa, lo que los Tribunales españoles consideran, en general, esencial al efecto es que los elementos del contrato no estén claramente determinados: si el inmueble está perfectamente descrito, y lo mismo puede decirse de la identificación de las partes y determinación del precio, la jurisprudencia, según hemos visto, viene considerando que estamos ante una compraventa propiamente dicha, ya que ésta se perfecciona por el mero consentimiento, y ello aunque las partes se refieran al acuerdo suscrito como reserva o promesa de venta.

Ahora bien, pese a en efecto, podemos extraer dicha conclusión, una vez analizada la postura de los tribunales, a la que, indudablemente, a nivel práctico hay que darle su merecida relevancia, toda vez que, en todo caso, si mediara conflicto habrá que estar al pronunciamiento del tribunal que conozca del asunto, lo cierto es que, como también observa PARRA LUCÁN ${ }^{23}$, esta calificación jurisprudencial como promesa o compraventa, según los casos, a efectos prácticos puede resultar irrelevante si los elementos de la compraventa están determinados, ya que tanto da que se condene a la parte al cumplimiento del contrato de promesa de venta celebrado, que se resuelva que realmente estamos ante una compraventa perfecta. Así, en la práctica, se obtendría el mismo resultado calificando el contrato como promesa bilateral, o como de compraventa, siempre que estén determinados los elementos esenciales y no sea necesario un nuevo acuerdo sobre los mismos por parte de los contratantes.

La afirmación anterior se fundamenta en lo establecido por el art. 708 de la Ley Enjuiciamiento Civil, ya que dicho precepto establece la posibilidad de que, en fase de ejecución de una sentencia, se pueda sustituir judicialmente la declaración de voluntad de aquella persona que no se aviene a prestarla voluntariamente. Al respecto, y precisamente respecto a una promesa de venta, en auto dictado el 1 de julio de 2009, la Audiencia Provincial de Madrid (Roj: AAP M 9883/2009), tras recordar que el Tribunal Supremo, desde 1950, viene considerando que, si los elementos esenciales que integran un contrato aparecen reflejados en el precontrato, "el Juez puede darlo por existente y actuar en consecuencia (STS 28 jun. 1974)”, sigue diciendo que, en tales casos, el art. 708.1 LEC dispone que si el demandado ha sido condenado en sentencia a emitir una concreta declaración de voluntad, si no lo hiciere en el plazo legal «el tribunal, por medio de auto, resolverá tener por emitida la declaración de voluntad». Por ello, entiende la Audiencia en su auto que sería mejor opción que la sentencia tuviera por existente el negocio jurídico dependiente de la declaración de voluntad a qué se condena, en lugar de obligar al sujeto a emitirla, ya que en principio, si los elementos del negocio están determinados, podría el Juez perfectamente condenar a la parte a cumplir los términos del mismo: "Como se ha dicho con incuestionable acierto: "basta fundar su decisión en el hecho de que no era preciso un nuevo consentimiento del autor de la promesa de contratar, por cuanto era suficiente el consentimiento prestado otorgarse el precontrato»".

${ }^{23}$ PARRA LUCÁN, M.A., "Promesa de compraventa, precontrato y cartas de intenciones en la jurisprudencia", Tratado de la compraventa. Homenaje al profesor Rodrigo Bercovitz, Dir. A.C.P., tomo I, Aranzadi, Pamplona, 2013, págs. 423 y 424 , 
La conclusión final que podemos extraer es que, independientemente de si en una eventual sentencia se resuelve que estamos ante una compraventa perfecta, o ante una promesa de venta, si todos los elementos del contrato están definidos, el resultado será el mismo, puesto que la condena, en el caso de la promesa de venta, obligaría al vendedor a suscribir el contrato definitivo, pudiéndose sustituir judicialmente la emisión de su declaración de voluntad, en ejecución de sentencia, conforme al citado art. 708 LEC. Si bien es cierto que considerarlo desde el principio como una compraventa perfecta puede ser más ventajoso para el comprador, ya que podría instar ejecución, solicitando directamente el cumplimiento de la obligación, y no la obtención de una declaración de voluntad, ya que en este último caso existe el riesgo para el adquirente de encontrarse, de nuevo, con una voluntad obstativa al cumplimiento, lo que le obligaría a acudir a un nuevo proceso declarativo, exigiendo la entrega.

\section{BIBLIOGRAFÍA}

ALONSO SAURA, M.P., "El tiempo en la entrega de la vivienda objeto de compraventa en proyecto o en construcción en situaciones de crisis económica", Discurso leído el día 30 de junio de 2011 en el acto de recepción como Académico de Número de la Real Academia de Legislación y Jurisprudencia de la Región de Murcia

ATAZ LOPEZ, J.,

- “Comentario a los arts. 1.445 a 1456 CC”, Comentarios al Código Civil, Dir. R.B.R.C., Tirant lo Blanch, Valencia, 2013.

- "Compraventa y contrato de obra futura", Tratado de la compraventa. Homenaje al profesor Rodrigo Bercovitz, Dir. A.C.P., tomo I, Aranzadi, Pamplona, 2013.

BORRELL SOLER, A., El contrato de compraventa según el Código Civil español, Bosch, Barcelona, 1952

DIÉZ PICAZO, L. y GULLÓN BALLESTEROS, A., Sistema de Derecho Civil, vol. II, Tecnos, Madrid, 1982

FERRÁNDIZ GABRIEL, J.R., “Compraventa de cosa futura”, El Contrato de Compraventa. Cuadernos de Derecho Judicial XXI, Consejo General del Poder Judicial, Madrid, 1993

MANRESA Y NAVARRO, J.M., Comentarios al Código Civil español, Reus, Madrid, 1969

MERIDA ABRIL, C., "El contrato de compraventa de inmuebles y su resolución", Derecho inmobiliario: Problemática actual, Manuales de Formación Continuada 50/2009, tomo II, Consejo General del Poder Judicial, Madrid, 2009

NAVARRO PEREZ, J.L., La compraventa civil. Antecedentes, comentario doctrinal, jurisprudencia y formularios, Comares, Granada, 1993

PARRA LUCÁN, M.A., "Promesa de compraventa, precontrato y cartas de intenciones en la jurisprudencia”, Tratado de la compraventa. Homenaje al profesor Rodrigo Bercovitz, Dir. A.C.P., tomo I, Aranzadi, Pamplona, 2013 
PERALES VISCASILLAS, P., "Hacia un nuevo concepto del contrato de compraventa", Revista Criterio Jurídico, $n^{o}$ 3, Pontificia Universidad Javeriana, Santiago de Cali, Colombia, 2013

PERLINGIERI, P., Il negozi su beni futuri, Vol I: La compraventita di cosa futura, Pubblicazioni della Facoltà Giuridica dell’Università di Napoli, Jovene, Nápoles, 1962

RODRIGUEZ MORATA, F., “Comentarios a los arts. 1445 a 1456 CC”, Comentarios al Código Civil, Coord. R.B.R.C., Aranzadi, Pamplona, 2009.

ROGEL VIDE, C., La compraventa de cosa futura, Bolonia, 1975.

RUBINO, D., La compravendita, Giuffré, Milán, 1952

TORRES LANA, J.A., "Perfección de la compraventa mediante el ejercicio de una opción", Tratado de la compraventa. Homenaje al profesor Rodrigo Bercovitz, Dir. A.C.P., tomo I, Aranzadi, Pamplona, 2013

TORRES LÓPEZ, A., "La protección del comprador de la vivienda en los momentos previos a la consumación del contrato", Cuadernos de Derecho Judicial 1/2009, Consejo General del Poder Judicial, Madrid, 2009 